\title{
Comparative Investigation of Polyphenylene Sulfide Polymer-Graphite Bipolar Plates for Fuel Cell Application
}

\author{
A. Dushina, B. Satola, A. Dyck, P. Wagner \\ DLR Institute of Networked Energy Systems, Carl-von-Ossietzky-Str. 15, D-26129 \\ Oldenburg, Germany
}

In this work two compression molded commercial polyphenylene sulfide (PPS) polymer-graphite composite bipolar plates (BPPs) with 15 and $20 \%$ of polymer binder material from two different manufacturers were employed for an analytical comparative investigation using physical and electrochemical analysis. Chemical stability of BPPs was investigated after storage in phosphoric acid. Corrosion resistance and electrochemical aging of the BPPs were studied by using linear sweep voltammetry, cyclic voltammetry and electrochemical impedance spectroscopy in phosphoric acid. In order to characterize the difference in physical properties water contact angle measurement and through-plane electrical conductivity experiments were performed. Comparison of BPPs revealed that the surface roughness and electrical conductivity is ca. $40 \%$ lower while acid uptake and hydrophilicity is ca. $35 \%$ higher for BPP with higher amount of PPS. Moreover, there was a trend of corrosion rate reducing for BPP with increased PPS content. This behaviour could be explained based on structure and electrical properties of the materials.

\section{Introduction}

The increasing interest in renewable energy sources has driven the development of high temperature polymer electrolyte membrane (HT-PEM) fuel cells regarding their minimal emissions, low weight and better tolerance to fuel impurities at temperature range of $130-180^{\circ} \mathrm{C}$. They efficiently convert chemical energy to electrical energy while using hydrogen supply from renewable energy sources such as wind, solar and biomass. These features allow reducing problems associated with fossil fuels for instance greenhouse gas emissions and air pollution $(1,2)$.

Despite this, two main limitations concerning high cost and insufficient durability under certain operating conditions are hindering the wide spread application of the HTPEM fuel cell. Thus, a significant amount of research has been focused on the development of individual components of the fuel cell including bipolar plates (BPP), catalyst layer and the membrane (1, 3-7).

BPPs are one of the key components of the HT-PEM fuel cell which play an important role in the development of fuel cell application. They should fulfil many functions in a fuel cell stack such as feeding $\mathrm{H}_{2}$ and $\mathrm{O}_{2}$ gases through the flow field upon 
operation, heat transfer, physical separation of individual fuel cells in series, collection and transport of electrons from anode to cathode of adjacent cells (1,3). Significant efforts have resulted in light-weight and cost effective BPPs for fuel cell applications (2, 8-11). In order to properly perform in a fuel cell, BPPs should provide mechanical, electrical, thermal and electrochemical stability of the system. Among the BPPs used in HT-PEM the composite BPPs are promising materials in which a polymer such as polyethylene, polypropylene, polyphenylene sulfide (PPS) or phenol formaldehyde resin provides the mechanical stability while graphite based components provide the electrical conductivity. The composite material has a good electrical conductivity, lower cost, higher flexibility and chemical stability, in comparison to metallic and graphite plates (1). Thus, polymer-graphite composite materials are becoming more popular as an alternative to metallic ones. However, some challenges such as higher thickness and weight in comparison to metallic bipolar plates are limiting the use of polymer-graphite plates in automotive application (1). In addition, it was reported that corrosion of carbon is taking place under fuel cell operating conditions (12-13). The mechanism of carbon corrosion can be expressed as Eq

$$
\mathrm{C}_{(\mathrm{s})}+2 \mathrm{H}_{2} \mathrm{O} \rightarrow \mathrm{CO}_{2(\mathrm{~g})}+4 \mathrm{H}^{+}+4 \mathrm{e}^{-}
$$

However, up to date only a limited amount of studies about stability of commercial polymer-graphite BPPs and their corrosion resistances in real fuel cells application are encountered in literature $(2,9,14)$. Therefore, in this study two BPPs produced by different industrial manufacturers were analytically investigated and comprehensively compared in terms of acid uptake, wettability, electrical conductivity, (electro)chemical stability and morphology. The corrosion behaviour of the material was evaluated by using potentiostatic as well as potentiodynamic methods. Scanning electron microscopy (SEM), confocal microscopy, energy-dispersive X-ray spectroscopy (EDX) analysis and $\mathrm{X}$-ray diffraction (XRD) were used to determine the morphology of the composites and to identify the chemical composition of the BPPs' surfaces.

\section{Experimental}

\section{$\underline{\text { BPP samples }}$}

The experiments were performed on compression molded and sandblasted BPPs delivered by two different companies. In this paper they are referred to as BPP-20 and BPP-15, respectively. BPP-20 contains $78 \%$ carbon, $20 \%$ PPS and $2 \%$ conductive filler, while BPP-15 contains $81 \%$ carbon, $15 \%$ PPS and $4 \%$ conductive filler. BPP-20 has a thickness of $1.5 \mathrm{~mm}$, while BPP-15 has a thickness of $3 \mathrm{~mm}$. Both BPPs with flow fields

channels were cut into $2 \mathrm{~cm}^{2}$ cuboids and $1 \mathrm{~cm}^{3}$ cubes and then cleaned in deionized water before they were further treated and investigated.

\section{Confocal microscopy}

In order to investigate the surface roughness confocal microscopy measurements were performed (Sensofar, PLu neox, Spain).The pristine sample was scanned with $100 \mathrm{x}$ 
magnification with the software SensoScan. The z-scan was performed using a $0.20 \mu \mathrm{m}$ step size. The root mean square surface roughness $(\mathrm{Sq})$ was calculated with the same software after levelling the confocal microscopy image.

\section{$\underline{\text { Acid uptake measurement }}$}

BPP samples with cube size of $1 \mathrm{~cm}^{3}$ were fully covered with $85 \%$ phosphoric acid and kept in autoclaves. The autoclaves were stored in a furnace over 500 hours at $160{ }^{\circ} \mathrm{C}$. After removal from the furnace and cooling down at the end of the test, the samples were taken out and excessive acid was removed by carefully wiping with paper cloth. Then they were analysed on their content of phosphoric acid. The content of phosphoric acid in BPPs after the storage at $160{ }^{\circ} \mathrm{C}$ for 500 hours was determined by titration with a defined solution of $0.01 \mathrm{~mol} / \mathrm{L}$ sodium hydroxide. The samples were stirred in $100 \mathrm{~mL}$ boiling water for 30 minutes (15). The solution was then titrated until the first transition point with an automatic titration system (TA 20 plus, SI Analytics) according to BASF test procedure (16).

\section{$\underline{\text { Scanning electron microscopy with energy dispersive X-ray spectroscopy }}$}

Morphological investigations and chemical composition of the BPP surfaces were performed by means of a SEM (NEON 40, Zeiss, Germany) with $30 \mathrm{kV}$ acceleration voltage and a SE2 detector. The chemical composition of the surface was determined by energy dispersive X-ray (EDX) coupled with SEM using silicon detector applying $20 \mathrm{kV}$.

\section{$\underline{X-r a y ~ d i f f r a c t i o n ~ m e a s u r e m e n t ~}$}

XRD of composite manually grinded by ceramic mortar and pestle was performed using the EMPYREAN Series 2 device (PANalytical B.V., The Netherlands) with $\mathrm{Cu} \mathrm{K} \alpha$ $\mathrm{X}$-ray source. Gonio scans were recorded in the $2 \theta$ diffraction angle range between $5^{\circ}$ and $40^{\circ}$ with $0.01^{\circ}$ steps.

\section{$\underline{\text { Water contact angle measurement }}$}

The static water contact angle $(\theta)$ measurement was performed by the sessile drop technique using $0.5 \mu \mathrm{L}$ drops of deionized water with the contact angle system OCA 15plus (Data-Physics, Germany) equipped with a Hamilton $500 \mu \mathrm{L}$ syringe, a CCD camera and the SCA20 software (version 2.0.0). The average values of the contact angle were obtained from three measurements per sample before and after corrosion test.

\section{Electrical conductivity measurement}

The electrical through-plane resistivity measurement was performed using Zwick/Roell zwickiLine Z1.0 (Figure 1). The sample with area $1 \mathrm{~cm}^{2}$ was fixed between two gold-coated stamps with a diameter of $25 \mathrm{~mm}$. The resistance was measured for three 
minutes at different compression forces from $0.1,0.5,0.8$ to $1.0 \mathrm{~N} \mathrm{~mm}^{2}$. In order to obtain a good surface connection between the solid stamps and the BPP sample the use of thin and flexible carbon paper gas diffusion layers (GDL), (QuinTech, Freudenberg) was necessary. At each compression load first two GDLs were measured and the resistance value was set to zero. Then the measurement was repeated for a BPP sample in between of two GDLs (Figure 1) in order to only obtain the resistance of the single BPP.

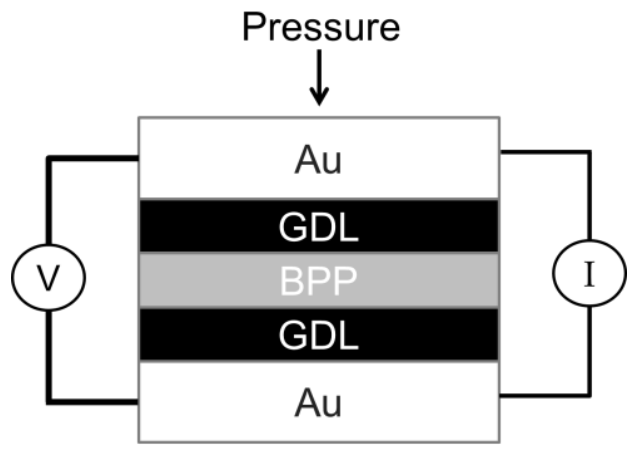

Figure 1. Schematic setup for through-plane resistivity measurement, where Au is a goldcoated stamp, GDL is a carbon paper of the gas diffusion layer and BPP is bipolar plate sample.

\section{$\underline{\text { Electrochemical measurements }}$}

All electrochemical measurements were realized in a conventional three electrode setup inside a Faraday cage and connected to a potentiostat/galvanostat (Solartron Analytical Modulab, UK) with a BPP as working electrode, the reversible hydrogen electrode (RHE) as reference and Pt mesh as a counter electrode. Prior to the measurements the electrolyte was flushed with $\mathrm{N}_{2}$ for $15 \mathrm{~min}$ and during the measurements the $\mathrm{N}_{2}$ atmosphere was maintained.

Before the electrochemical measurements the pristine BPP samples were cycled for 100 cycles in the potential range from open circuit voltage (OCV) to $+1.2 \mathrm{~V}$ vs. RHE in $0.5 \mathrm{M} \mathrm{H}_{3} \mathrm{PO}_{4}\left(\geq 99 \%\right.$, Sigma- Aldrich, Germany) with a scan rate of $100 \mathrm{mV} \mathrm{s}^{-1}$ in order to pre-activate the hydrophobic sample surface and, therefore, to observe reproducible and well-defined electrochemical behaviour. The pre-activated BPPs were analysed by cyclic voltammetry (CV) in $0.5 \mathrm{M} \mathrm{H}_{2} \mathrm{SO}_{4}(>95 \%, 1.830 \mathrm{~g} / \mathrm{mL}$, Fisher Scientific, UK). $0.5 \mathrm{M} \mathrm{H}_{2} \mathrm{SO}_{4}$ electrolyte was specifically selected for comparison reasons because the electrochemical behaviour of polymer-graphite composite BPPs in this media has already been established in literature (2). A potential range from 0.25 to $1.10 \mathrm{~V}$ vs. RHE with scan rates of 10,20 and $50 \mathrm{mV} / \mathrm{s}$ at room temperature $\left(\sim 22^{\circ} \mathrm{C}\right)$ was used for this experiment. Every $10^{\text {th }}$ cycle was plotted and compared for each BPP.

Electrochemical aging of pristine BPPs was performed by using CV in $15 \mathrm{M} \mathrm{H}_{3} \mathrm{PO}_{4}$ solution at room temperature $\left(\sim 22{ }^{\circ} \mathrm{C}\right)$ in the potential range 0.25 to $1.10 \mathrm{~V}$ vs. RHE with a scan rate of $10 \mathrm{mV} \mathrm{s}^{-1}$ for 1000 cycles. The first and the last cycles were compared. 
For the chemical corrosion test, pristine BPPs were immersed separately in $0.5,5,10$ and $\quad 15 \mathrm{M} \mathrm{H}_{3} \mathrm{PO}_{4}$ for $10 \mathrm{~h}$ and after that the linear sweep voltammetry (LSV) in the potential range from $+1.2 \mathrm{~V}$ to $\mathrm{OCV}$ was measured with a scan rate of $1 \mathrm{mV} \mathrm{s}^{-1}$ for each sample by maintaining the same electrolyte acid concentrations from the chemical test. Thereafter, the corrosion rates were determined from the polarization curves. The data were obtained using Tafel extrapolation method in accordance to the Eq. [2]:

$$
\eta=a+b * \log i
$$

where $\eta$ is overpotential, $a$ and $b$ are constants, $i$ is current density in $\mathrm{A} \mathrm{m}^{-2}$.

For the extrapolation it was assumed that the surface oxidation occurs in accordance with Eq. [1] leading to $\mathrm{CO}_{2}$ evolution on the anode side while on the cathode side hydrogen reduction reaction takes place.

\section{Results and Discussion}

First, both pristine BPP types were examined by confocal and scanning electron microscopy in order to investigate their surface structure and morphology, respectively. The calculated surface roughness of BPP-20 reaches $590 \mathrm{~nm}$. Thus, it is smoother than BPP-15 with a roughness of $967 \mathrm{~nm}$. Figure 2 shows SEM images of the pristine BPPs. It can be observed that the pristine BPP-20 has a rather smooth surface in comparison to BPP-15 which shows randomly distributed dents with diameters in two-to three-digits in $\mu \mathrm{m}$ scale. This difference is in good agreement with the confocal microscopy analysis and can be associated to the higher amount of the thermoplastic polymer PPS in BPP-20 that provides more homogenous surface formation (17).

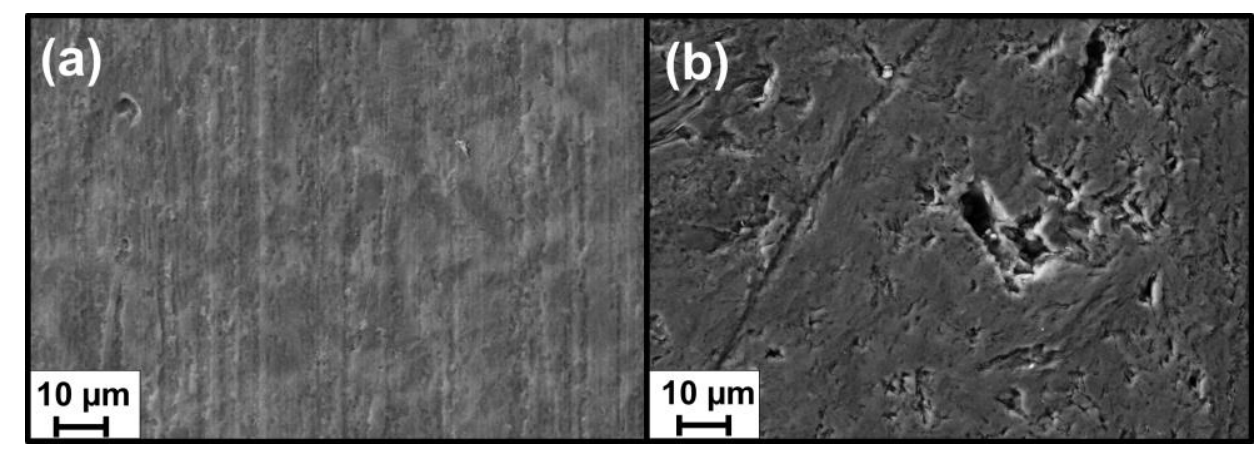

Figure 2. SEM images of pristine a) BPP-20 and b) BPP-15.

Further comparison of pristine BPP material was carried out by XRD of their composite after grinding in order to investigate their crystalline characteristics. Figure 3 shows the resulted XRD patterns. First it can be seen that both samples have similar sharp peaks indicating crystalline structure of the material. Moreover, the calculated crystal size for BPP-20 and BPP-15 powders appear comparable and equal to $17.5 \mathrm{~nm}$ and $19.2 \mathrm{~nm}$, respectively. For both samples reflections (110) and (111/200) around $20^{\circ}$ are referred to PPS, while (002) reflection at $27^{\circ}$ is associated to carbon (18-19). 


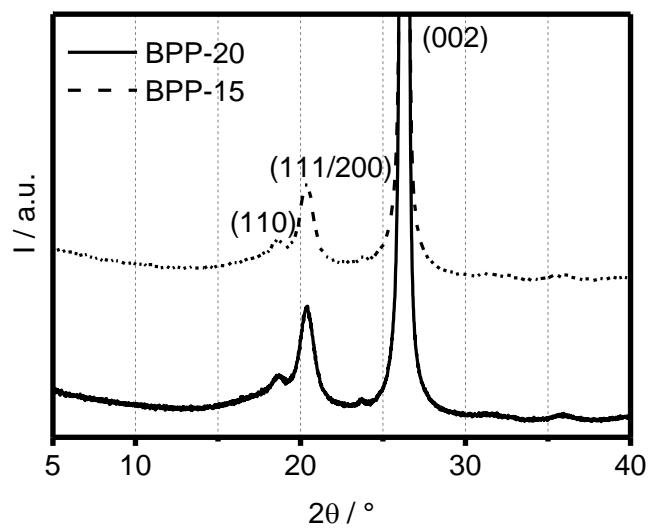

Figure 3. XRD patterns of BPP-20 and BPP-15 composite powders.

The determination of remaining acid in BPPs after storage in hot phosphoric acid can provide information about the acid uptake of BPPs that could further influence on their chemical stability. BPP-20 shows higher acid uptake $\left(3.5 \mathrm{mg}_{\mathrm{PA}} \mathrm{g}^{-1}\right)$ in comparison to BPP-15 (2.15 mg PA $\left.^{-1}\right)$. The difference could be associated to different wetting properties of both BPPs. Thus, the water contact angle was measured for both samples (Figure 4).

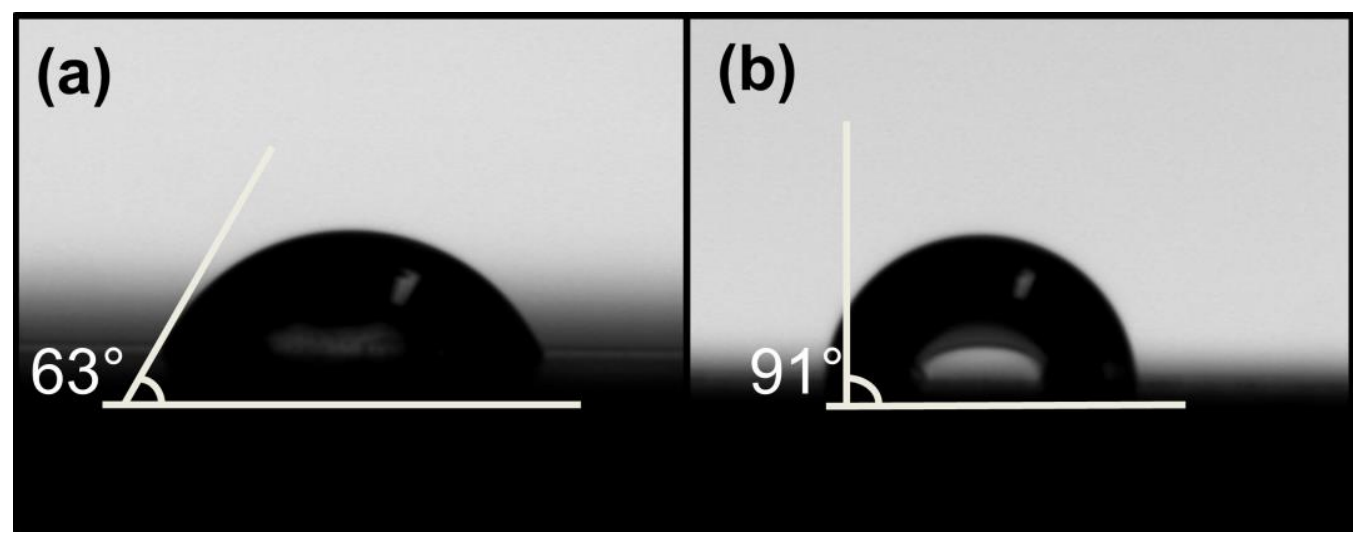

Figure 4. Water contact angle ( $\left.\theta_{\text {wca }}\right)$ of (a) BPP-20 and (b) BPP-15.

In this experiment the static water contact angle $\left(\theta_{\text {wca }}\right)$ represents a quantitative measure of wetting of solid surfaces where contact angles below $90^{\circ}$ indicate hydrophilic surfaces while values above $90^{\circ}$ give evidence for hydrophobic ones. A higher contact angle of $(91 \pm 4)^{\circ}$ was observed for BPP-15 indicating its more hydrophobic surface in comparison to BPP-20 which has a value of $(63 \pm 4)^{\circ}$. This observation is in good agreement with the higher phosphoric acid uptake of BPP-20 due to its stronger wetting properties. The wetting behavior of BPPs is a complex phenomenon which could be influenced by several physical and chemical factors including surface roughness, heterogeneity, particle size and shape, chemical composition as well as surface morphology $(14,20)$. Further the last two factors will be discussed more in detail.

Through-plane electrical conductivity of the pristine BPPs was measured at room temperature as a function of compression force. As it can be seen from Figure 5 for both 
samples the conductivity is increasing with higher pressure. This fact is mainly related to lower contact resistance between the gold stamps, GDLs and BPPs with higher pressure. Moreover, the electrical conductivity of BPP-20 is lower compared to BPP-15 due to the fact that it contains higher amount of PPS and lower amount of conductive filler (17).

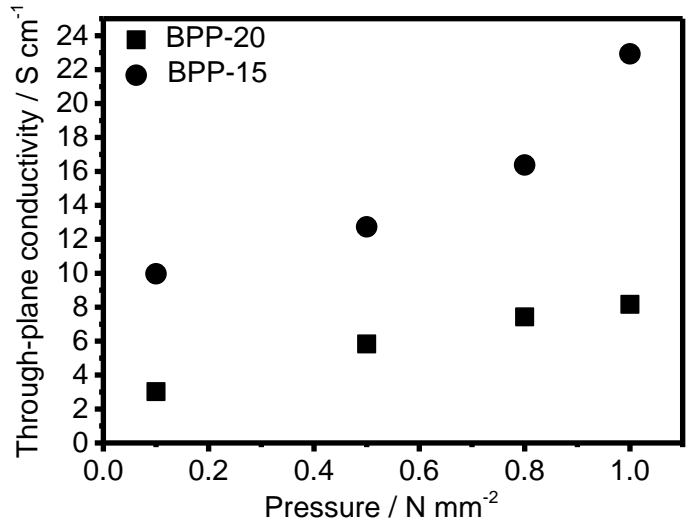

Figure 5. Through-plane electrical conductivity of BPP-20 and BPP-15 as a function of pressure at room temperature.

Next, the BPPs were explored by electrochemical measurements with the aim to study the oxidation behavior of the materials. Figure 6 shows CVs of pre-activated BPP20 and BPP-15 in $\mathrm{N}_{2}$-saturated $0.5 \mathrm{M} \mathrm{H}_{2} \mathrm{SO}_{4}$. Both samples at each scan rate display the typical pseudo capacitance at $\sim 0.4-0.6 \mathrm{~V}$, related to the quinone/hydroquinone (Q/HQ) surface redox reaction indicating surface oxidation and degradation (22-23). As proposed by Choo, several functional groups such as carbonyl, carboxyl or ester can be formed on BPP surface during oxidation (24). Moreover, it was observed that the double layer capacitance of both samples is increasing with higher scan rate. This behavior can be associated to a thicker diffusion layer formed at lower scan rates and therefore smaller flux of the electrons towards the BPP surface.
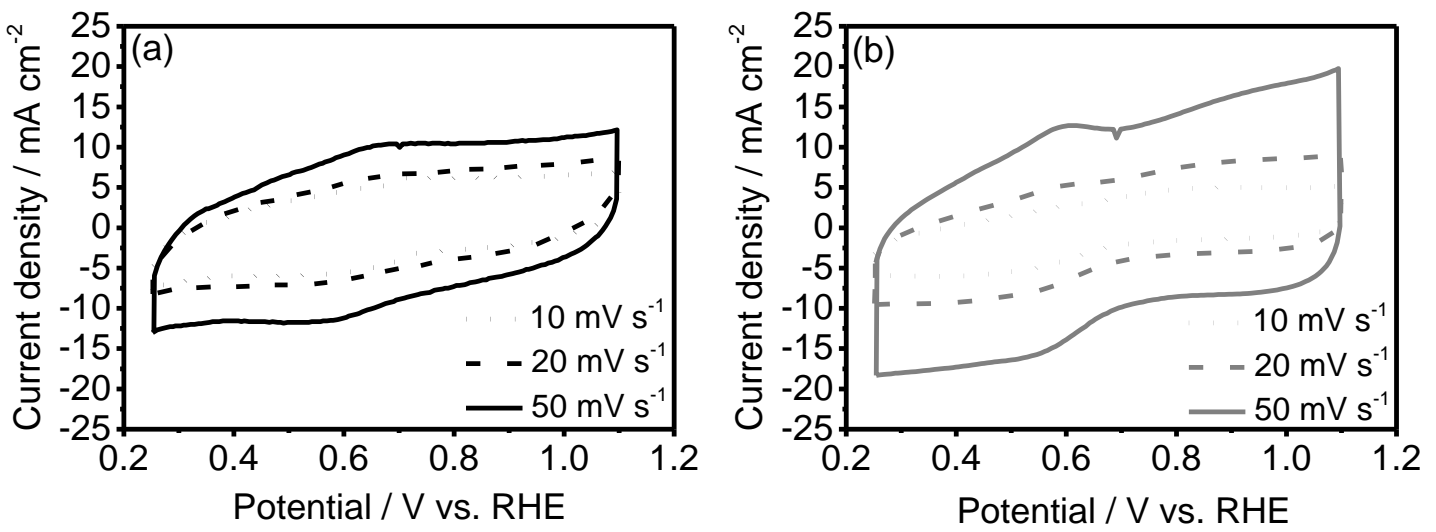

Figure 6. $\mathrm{CV}$ of a) BPP-20 and b) BPP-15 in $\mathrm{N}_{2}$-saturated $0.5 \mathrm{M} \mathrm{H}_{2} \mathrm{SO}_{4}$ at different scan rates.

Furthermore, electrochemical aging was performed for both samples by using CVs with a scan rate of $10 \mathrm{mV} \mathrm{s}^{-1}$ for 1000 cycles in $15 \mathrm{M} \mathrm{H}_{3} \mathrm{PO}_{4}$. In Figure 7 the first and last 
CV of BPP-20 and BPP-15 are shown for comparison. In both cases the pseudo capacitance is located between $\sim 0.4-0.6 \mathrm{~V}$ which is attributed to $\mathrm{Q} / \mathrm{HQ}$ redox reaction. The peaks are more pronounced after 1000 cycles in comparison to the first one giving evidence for surface oxidation and thus degradation of composite material. Since BPP-15 contains more graphite material than BPP-20, a larger interface area between the electrolyte and the graphite particles can be formed on the surface of BPP-15 which leads to more active sites. Thus, it shows higher double layer capacitance and higher increase in $\mathrm{Q} / \mathrm{HQ}$ redox activity than BPP-20.
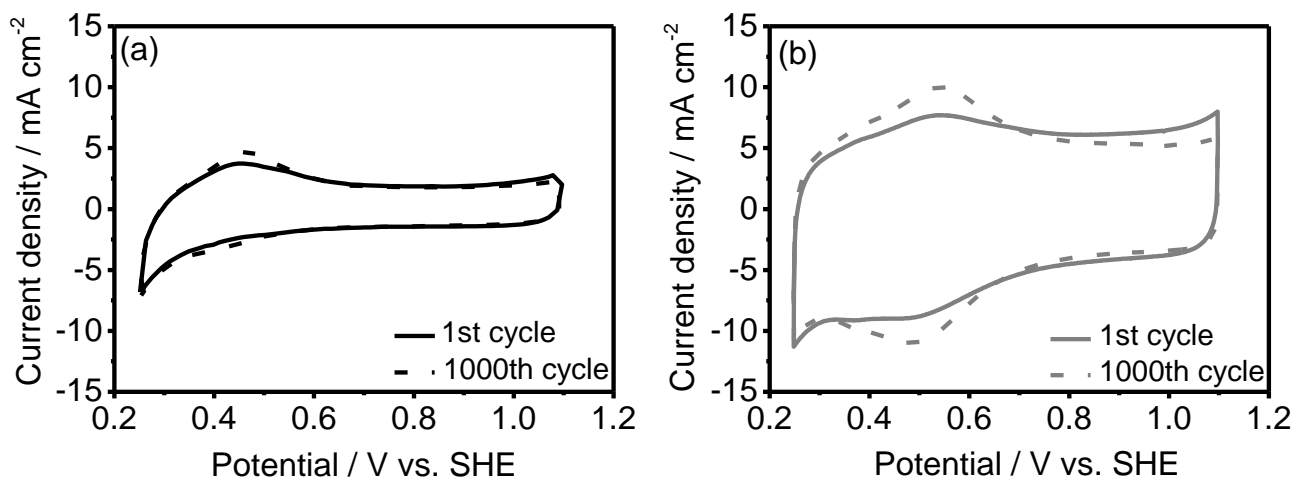

Figure 7. CVs of a) BPP-20 and b) BPP-15 in $\mathrm{N}_{2}$-saturated $15 \mathrm{M} \mathrm{H}_{3} \mathrm{PO}_{4}$ at $10 \mathrm{mV} \mathrm{s}^{-1}$. The first and 1000th cycles are shown.

To elucidate morphology changes of BPPs after electrochemical aging, SEM and EDX analysis was conducted. Figure 8 shows SEM images of the aged samples. It can be seen that after electrochemical aging, both samples show an increase in surface roughness caused by the formation of dents within the composite structure in comparison to the pristine ones (Figure 2). It is evident that the corrosion effects are more pronounced for BPP-15. In addition, the surface of BPP-15 contains more white spots than BPP-20 which could be an evidence of carbon oxidation. Thus, BPP-15 is more susceptible to degradation in accordance with CV measurements.

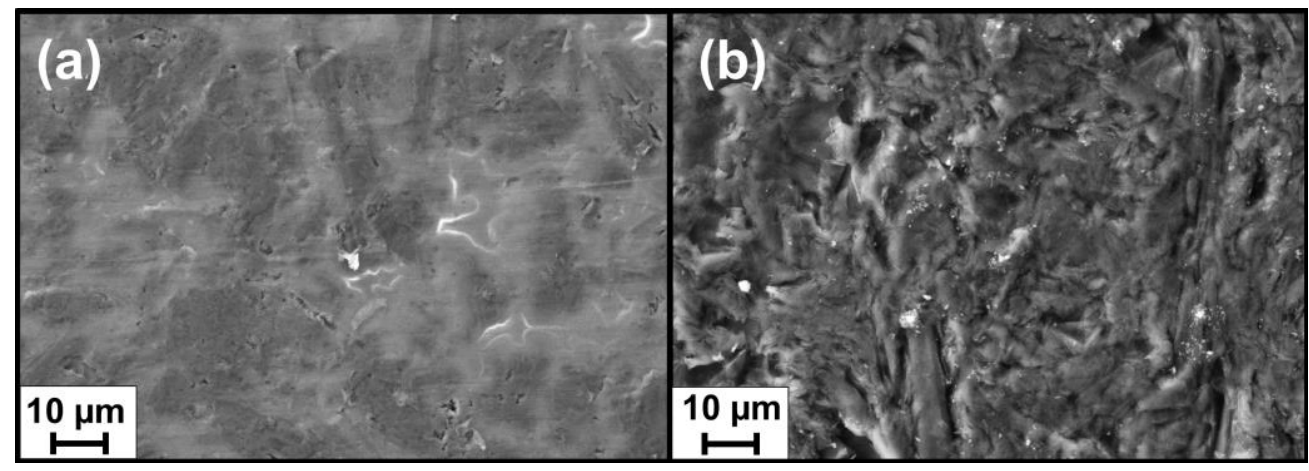

Figure 8. SEM images of the BPP-20 (a) and BPP-15 (b) after electrochemical corrosion.

EDX was performed for both BPPs before and after aging in order to identify the elemental composition of their surfaces (Figure 9). It can be seen that pristine BPP-20 with higher PPS content shows a higher sulphur peak in comparison to pristine BPP- 15 . Moreover, the amount of sulphur is increasing within the C:S ratio for BPP-20 after aging. 
The detection of higher sulphur content could be related to augmented acid uptake due to its hydrophilic surface properties in good agreement with the contact angle measurements. The oxygen peak is rather negligible for BPP-20. However, for BPP-15 it is significantly increasing after corrosion (Figure 9 (d)). The presence of oxygen on its surface could be due to introduction of new oxygen functional groups during corrosion which indicates more favorable carbon oxidation of BPP-15 compared to BPP-20. This result confirms the observation of pseudo capacitance behavior in the $\mathrm{CV}$ diagrams.
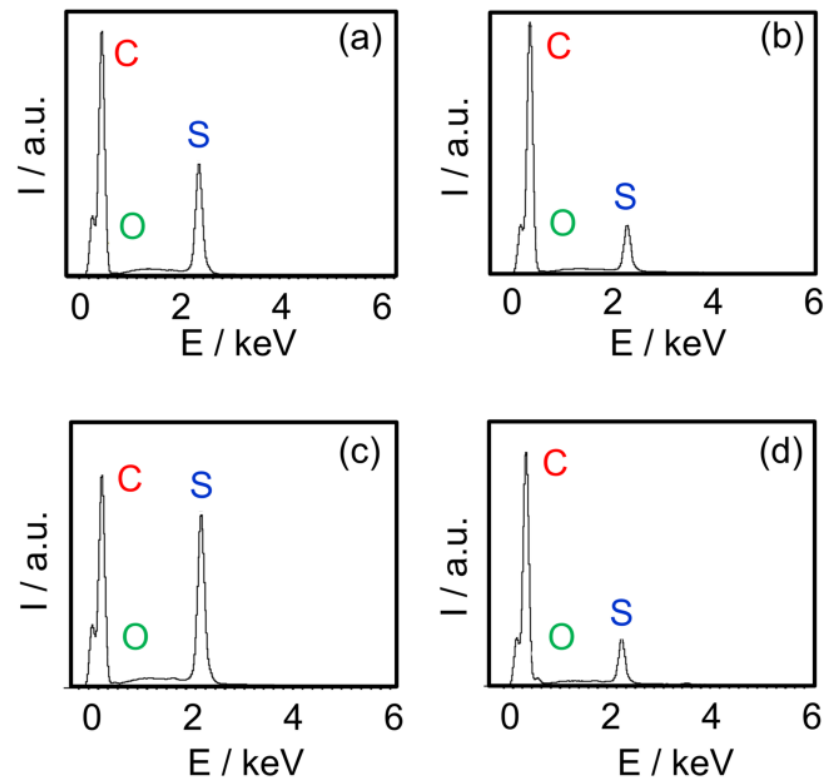

Figure 9. EDX spectra before $(a, b)$ and after $(c, d)$ electrochemical corrosion of BPP-20 $(\mathrm{a}, \mathrm{c})$ and BPP-15 (b, d), respectively.

For deeper investigation of the electrochemical resistivity of BPPs a linear sweep voltammetry was performed at $1 \mathrm{mV} \mathrm{s}^{-1}$. Figure 10 shows the LSV of BPP-20 and BPP15 in different concentrations of $\mathrm{H}_{3} \mathrm{PO}_{4}$ electrolyte. It can be observed that BPP-20 in 0.5 $\mathrm{M} \mathrm{H}_{3} \mathrm{PO}_{4}$ presents the best stability with almost negligible oxidation current during the scan. By changing the electrolyte concentration to $5 \mathrm{M}$ and $10 \mathrm{M}$ an increase of the current at potential starting at $1 \mathrm{~V}$ is obtained due to surface oxidation. When the concentration of electrolyte reaches $15 \mathrm{M} \mathrm{H}_{3} \mathrm{PO}_{4}$ a sharp increases of the oxidation current at around $0.75 \mathrm{~V}$ is observed. No other clear oxidation peaks during the scan are observed for BPP-20. 

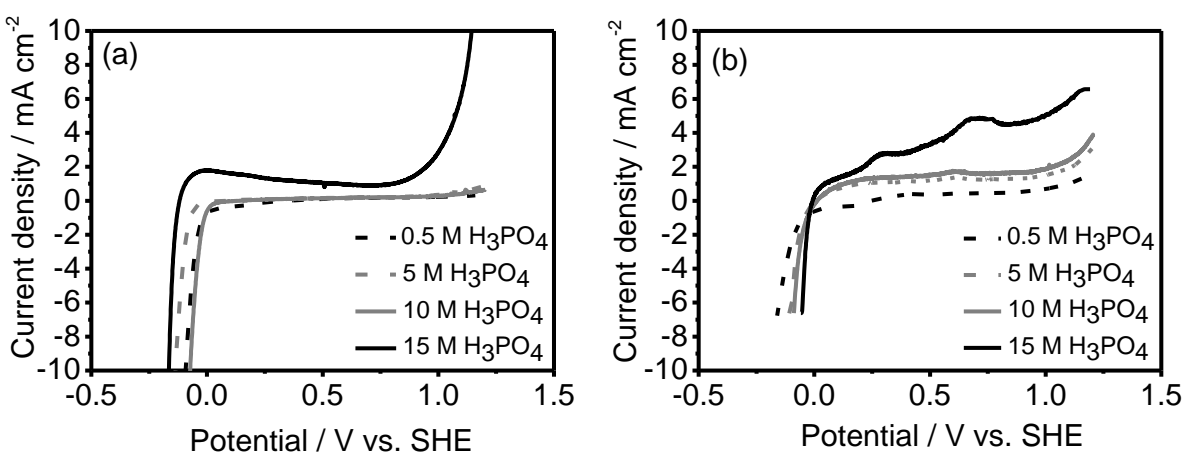

Figure 10. LSV of a) BPP-20 and b) BPP-15 in different concentrations of $\mathrm{H}_{3} \mathrm{PO}_{4}$ measured at room temperature with a scan rate of $1 \mathrm{mV} \mathrm{s}^{-1}$.

In the case of BPP-15 in the electrolytes with acid concentration from $0.5 \mathrm{M}$ to $10 \mathrm{M}$ the oxidation current increases starting at $0.95 \mathrm{~V}$. In contrary, for $15 \mathrm{M} \mathrm{H}_{3} \mathrm{PO}_{4}$ the increase of current is already visible at around $0.1 \mathrm{~V}$ indicating the start of the oxidation process already at lower potential. Moreover, two current peaks at around 0.28 and 0.75 $\mathrm{V}$ are clearly visible in $15 \mathrm{M} \mathrm{H}_{3} \mathrm{PO}_{4}$ electrolyte that could be associated to two steps of surface oxidation (12).

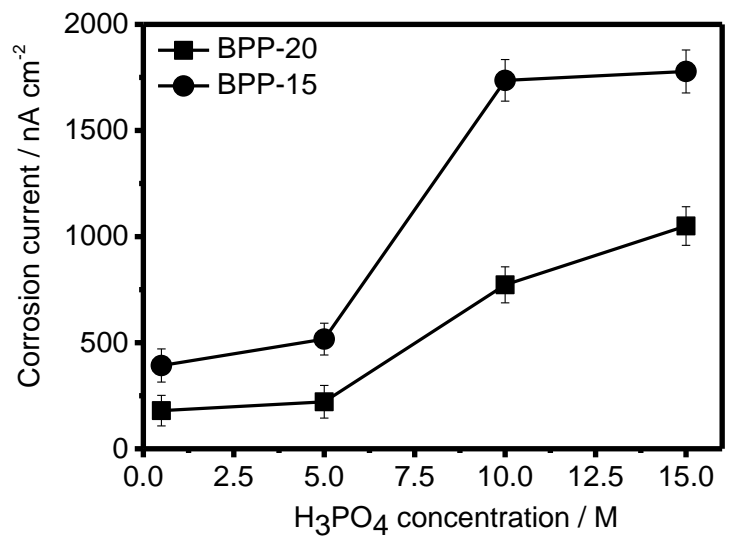

Figure 11. Corrosion current as a function of phosphoric acid concentration of BPP-20 and BPP-15 measured at room temperature.

Further, the corrosion rates were determined from the polarization curves based on the determination of the oxidation current at the corrosion potential from the Tafel slopes. The Tafel relationship can be obtained only when the oxidation current becomes insignificant with respect to the reduction current. Figure 11 shows the corrosion rates obtained from the Tafel slopes as a function of phosphoric acid concentration. It can be seen that with higher concentration of phosphoric acid the corrosion current is also increasing. Thus, in more aggressive electrolyte media the rate of material degradation is higher. It is also evident that the corrosion current of BPP-15 is higher than of BPP-20. Thus, higher corrosion resistance of BPP-20 could be related to more PPS content. Firstly, the polymer is electrochemically inactive and thus the surface area of BPP-20 contains less electroactive graphite particles compared to BPP-15. Secondly, the organic PPS matrix adds mechanical strength to the compound material and leads to higher structural 
homogeneity with lower roughness as indicated by confocal and scanning electron microscopy.

The standard of Department of Energy, US, requests corrosion current densities lower than $1 \mu \mathrm{A} \mathrm{cm}^{2}$ (25) for the application of BPPs in fuel cells. However, this standard is not fully applicable for comparison reasons of the present study since different electrolytes and operation conditions were used in the experiments.

Table I summarized the main quantitative parameters of the extensive testing methods of the BPPs. It can be seen that higher amount of the PPS binder (BPP-20) resulted in reduced surface roughness, hydrophobicity (water contact angle) and corrosion rate. On the other hand, the BPPs with lower content of binder (BPP-15) have better electrical conductivity and lower acid uptake. Therefore, for real fuel cells application the optimized ratio of graphite to PPS should be chosen in order to balance electrical conductivity and electrochemical stability properties.

TABLE I. Summary of the main properties of the extensive testing methods of BPP-20 and BPP-15.

\begin{tabular}{|c|c|c|}
\hline Properties & BPP-20 & BPP-15 \\
\hline Surface roughness, nm & 590 & 967 \\
\hline Acid uptake, $\mathrm{mg}_{\mathrm{PA}} \mathrm{g}^{-1}$ & 3.5 & 2.15 \\
\hline Water contact angle, ${ }^{\circ}$ & 63 & 91 \\
\hline $\begin{array}{l}\text { Electrical conductivity at } 0.1 \mathrm{~N} \mathrm{~mm}^{-2} \text {, } \\
\qquad \mathrm{S} \mathrm{cm}^{-1}\end{array}$ & 2.7 & 10.1 \\
\hline $\begin{array}{c}\text { Corrosion current in } 15 \mathrm{M} \mathrm{H}_{3} \mathrm{PO}_{4} \text {, } \\
n \mathrm{nA} \mathrm{cm}^{-2}\end{array}$ & 1048 & 1780 \\
\hline
\end{tabular}

\section{Conclusions}

In this work two polymer-graphite BPPs with different contents of graphite and PPS were treated chemically and electrochemically in phosphoric acid and comprehensively compared in terms of their morphological, physical and (electro)chemical properties.

The pristine BPP-15 with higher content of graphite shows higher electrical conductivity probably due to better graphite particle connectivity. In addition, it has a higher surface roughness, is more hydrophobic and shows less acid uptake in comparison to the sample with higher PPS content. The different surface roughness could be attributed to the varying production processes and material compositions. The higher water contact angle of the graphite rich sample might be a result of morphology properties or chemical surface composition. Furthermore, the lower acid uptake is directly related to its higher hydrophobicity and thus to lower wettability of the sample. However, with higher graphite content the corrosion rate of the BPP-15 was more pronounced which was shown by EDX measurements and increased Q/HQ peak intensity in the CVs after electrochemical aging related to oxygen functional groups on the surface. In addition, SEM imaging revealed an increase in surface roughness after aging which was more pronounced for the BPP-15 sample with higher graphite content. Therefore, a higher PPS content leads to higher degradation protection of the BPP since less graphite is available for corrosion attack. 
This work gives a contribution on the evaluation of polymer-graphite BPP properties that can be considered as suitable measure for selection of appropriate BPPs for application in fuel cells. It was shown that the choice of graphite to PPS ratio in BPPs is a balancing act between electrical conductivity and electrochemical stability properties. Therefore, both investigated samples fulfil other advantages and shall be precisely selected in order to meet different needs in fuel cell applications.

\section{Acknowledgments}

The authors thank Dana Schonvogel for the XRD measurement, Nadine Pilinski for the acid uptake experiment and Stefanie Laue for the SEM and EDX analysis. The

authors thank the German Ministry of Economics and Energy for financial support in the framework of the project QUALIFIX under grant No. 03Et6046A.

\section{References}

1. S. S. Araya, F. Zhou, V. Liso, S. L. Sahlin, J. R. Vang, S. Thomas, X. Gao, C. Jeppesen, S. K. Kær, Int. J. Hydrog. Energy, 41, 21310 (2016).

2. M. C. L. Oliveira, I. J. Syeg, G. Ett, R. A. Antunes, Int. J. Hydrog. Energy, 39, 16405 (2014).

3. T. Cruz-Gonzales, Bachelor thesis, Massachuesetts Institute of Technology (Massachusetts), (2004).

4. J. A. Asensio, E. M. Sanchez, P. Gomez-Romero, Chem. Soc. Rev., 39, 3210 (2010).

5. F. A. de Bruijn, V. A. T. Dam, G. J. M. Janssen, Fuel Cells, 1, 3 (2007).

6. B. Dursun, F. Yaren, B. Unveroglu, S. Yazici, F. Dundar, Fuel Cells, 14, 862 (2014).

7. H.-C. Kuan, C.-C. M. Ma, K. H. Chen, S.-M. Chen, J. Power Sources, 134, 7 (2004).

8. L. Nguyen, F. Mighri, Y. Deyrail, S. Elkoun, Fuel Cells, 6, 638 (2010).

9. P. J. Hamilton, B. G. Pollet, Fuel Cells, 4, 489 (2010).

10. B. K. Kakati, V. Mohan, Fuel Cells, 1, 45 (2008).

11. T. S. K. Raunij, R. K.Gautam, V. M. Bhradwaj, N. Nandikesan, M. Shaneeth, S. C. Sharma, A. Verma, Fuel Cells, 16, 801 (2016).

12. T. Engl, L. Gubler, T. J. Schmidt, J. Electrochem. Soc., 162, F291 (2015).

13. L. Castanheira, Ph.D. Thesis, University of Grenoble, France (2016).

14. B. Satola, C. N. Kirchner, L. Komsiyska, G. Wittstock, J. Electrochem. Soc., 163, A2318 (2016).

15. N. Pilinski, M. Rastedt, P. Wagner, ECS Transactions, 69, 323(2015).

16. BASF fuel cell, in BASF Stack Handbook: How to build, test, and diagnose high temperature PEM fuel cell stacks with Celtec (R) P1100 W, p. 29.

17. R. Yeetsorn, M.W. Fowler, C. Tzoganakis in Nanocomposites with Unique Properties and Applications in Medicine and Industry, (Eds. Dr. John Cuppoletti), InTech (2011).

18. T. Saito, M. Okamoto, R. Hiroi, M. Yamamoto, T. Shiroi, Polymer, 48, 4143 (2007).

19. G. Krishnamurty, R. Namitha, J. Chil. Chem.Soc., 58, 3 (2013). 
20. T. T. Chau, V. J. Bruckard, P.T.L. Koh, A.V. Nguyen, Ad. Colloid Interface Sci., 150, 106 (2009).

21. B. Avasarala, P. Haldar, J. Power Sources, 188, 225 (2009).

22. F. Forouzandeh, D. Banham, F. Feng, X. Li, S. Ye, V. Birss, ECS Transactions, 58, 1739 (2013).

23. B. Satola, L. Komsiyska, G. Wittstock, J. Electrochem. Soc., 165, A963 (2018).

24. H.-S. Choo, T. Kinumoto, S.-K. Jeong, Y. Iriyama, T. Abe, Z. Ogumi, J. Electrochem. Soc., 154, B1017 (2007).

25. S. Liao, C. Yen, C. Weng, Y. Lin, C. Ma, C. Yang, M. Tsai, M. Yen, M. Hsiao, S. Lee, X. Xie, Y. Hsiao, J. Power Sources, 185, 1225 (2008). 